Thorax (1970), 25, 97.

\title{
Bilateral pulmonary varicosities associated with coarctation of the aorta
}

\author{
GHASSAN RIZK, RAFIK MELHEM, IBRAHIM DAGHER \\ Departments of Radiology and Surgery, American University Hospital, Beirut, Lebanon
}

\begin{abstract}
Varicosities of the pulmonary vein are rare. Twenty-eight cases confirmed anatomically or by angiography have been reported. In this paper the authors report a rather unique patient who had bilateral varices of the lungs in conjunction with coarctation of the aorta. The plain film and angiographic features of pulmonary varices are discussed. A brief review of the cases reported previously is also presented.
\end{abstract}

\section{CASE HISTORY}

K. K.. a 25-year-old man, was referred to the American University Hospital with the diagnosis of coarctation of the aorta. A pre-employment chest radiograph taken four years previously had shown 'a rounded density in the right base'. Physical examination at that time revealed systemic hypertension considered to be secondary to aortic coarctation. He was symptom free, and his family history was negative.

On physical examination the pertinent findings were a grade II systolic murmur at the base of the heart radiating to the neck, a blood pressure of $170 /$ $100 \mathrm{~mm}$. $\mathrm{Hg}$ in the right arm, and $95 / 65 \mathrm{~mm}$. $\mathrm{Hg}$ in the right leg. An anterior film of the chest (Fig. 1) showed prominence of the left ventricle, dilatation of the aortic arch, and minimal notching of the right sixth rib. There was a 1/5-in. lobulated density apparently vascular in nature adjacent to the lower pole of the right hilum. A suspicious similar density was seen on the left side behind the heart shadow. These lesions changed in size during the Valsalva and Muller's manœuvres.

A venous angiogram (Fig. 2) showed the described densities to be dilated, tortuous pulmonary veins draining the lower lobes. These vessels opacified six seconds after the injection, the opaque material having already completely cleared the pulmonary arteries. They remained opaque for a longer time than the upper lobe veins.

A thoracic catheter aortogram (Fig. 3) was then performed and demonstrated a short segment coarctation just distal to the origin of the left subclavian artery with post-stenotic dilatation.

The coarcted aortic segment was resected through a left thoracotomy and at operation the left pulmonary varix was identified and was left undisturbed.

The patient had a smooth post-operative recovery. His blood pressure dropped to the normal level of $120 / 75 \mathrm{~mm}$. Hg. His pulmonary varices remained symptomless on subsequent follow-up.

\section{BRIEF REVIEW OF THE LITERATURE}

Gimes and Horváth (1958) credit Puchelt with having described, in 1843 , ectasia of the pulmonary vein in a newborn baby who had multiple varices in several organs and who died from intestinal haemorrhage.

Hedinger described a second case as a necropsy finding in an adult in 1907. In the following 44 years, five more cases of pulmonary varices discovered at necropsy were described (Case Rezords of the Massachusetts General Hospital, 1951 ; Jacchia, 1936 ; Klinck and Hunt, 1933 ; Nauwerck, 1923 ; Neiman, 1934).

Mouquin, Hébrard, Damasio, Jouvet, Durand, and Piéquet diagnosed the first case in a living patient by angiography in 1951 ; and since then the condition has been recognized more frequently and reported in small series (Bryk and Levin, 1965 ; Nelson, Hall, and Garcia, 1966 ; Poller and Wholey, 1966 ; Hipona and Jamshidi, 1967).

So far 28 cases, including ours, confirmed either anatomically or angiographically, have been described. Two other cases in which a probable diagnosis was made by tomography have also been reported (Gimes and Horváth, 1958 ; Schulze, 1956). The last two as well as Puchelt's case, to whose original report we had no access, are not included in the following analysis.

The sex incidence was 13 males to 15 females. The distribution in the lungs was as follows: right lower lobe, 17 cases; left upper lobe, 8 cases ; right upper lobe, 1 case ; left lower lobe, 1 case ; both lower lobes, 1 case. The youngest patient was 7 years old and the oldest 62 years old.

Four patients had mitral valve disease with pulmonary venous hypertension (Bryk and Levin, 


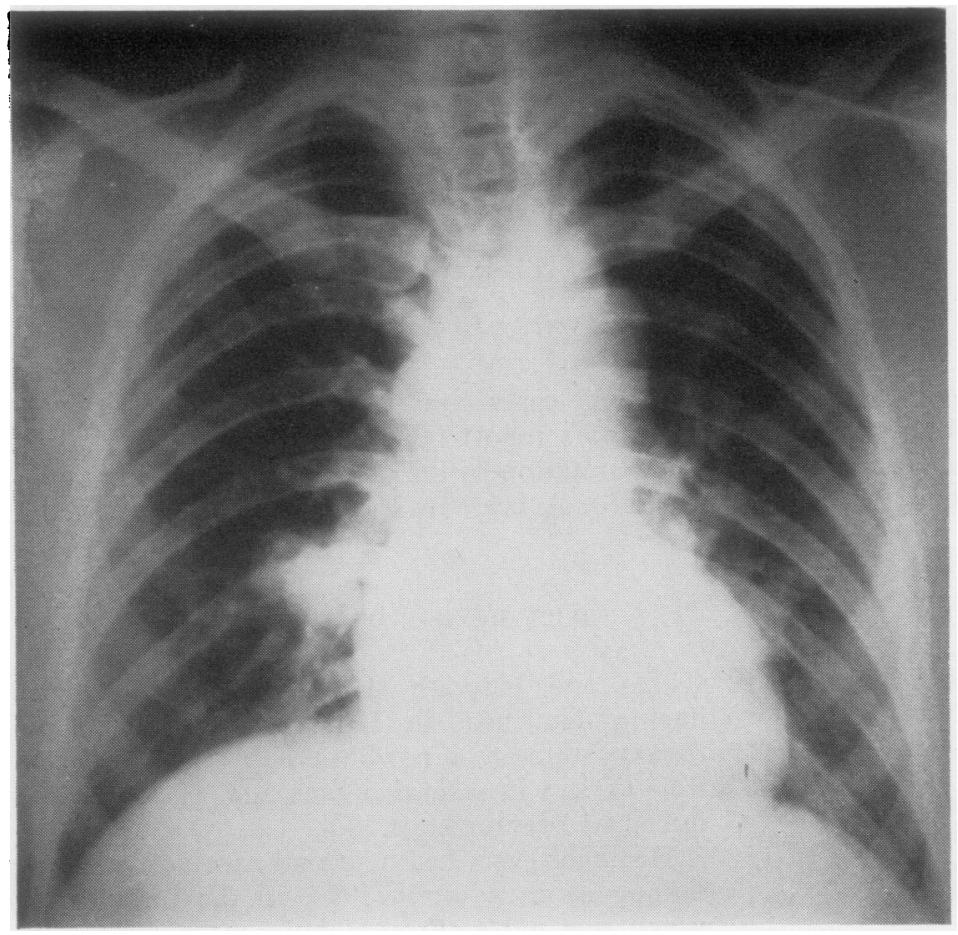
FIG. 1. Postero-anterior chest film. The
lobulated density in the right base - is apparent. The lesion behind the heavt is barely identifiable.

FIG. 2. Pulmonary angiogram-venous phase. The varicose lower lobe veins correspond to the densities found on the chest film.

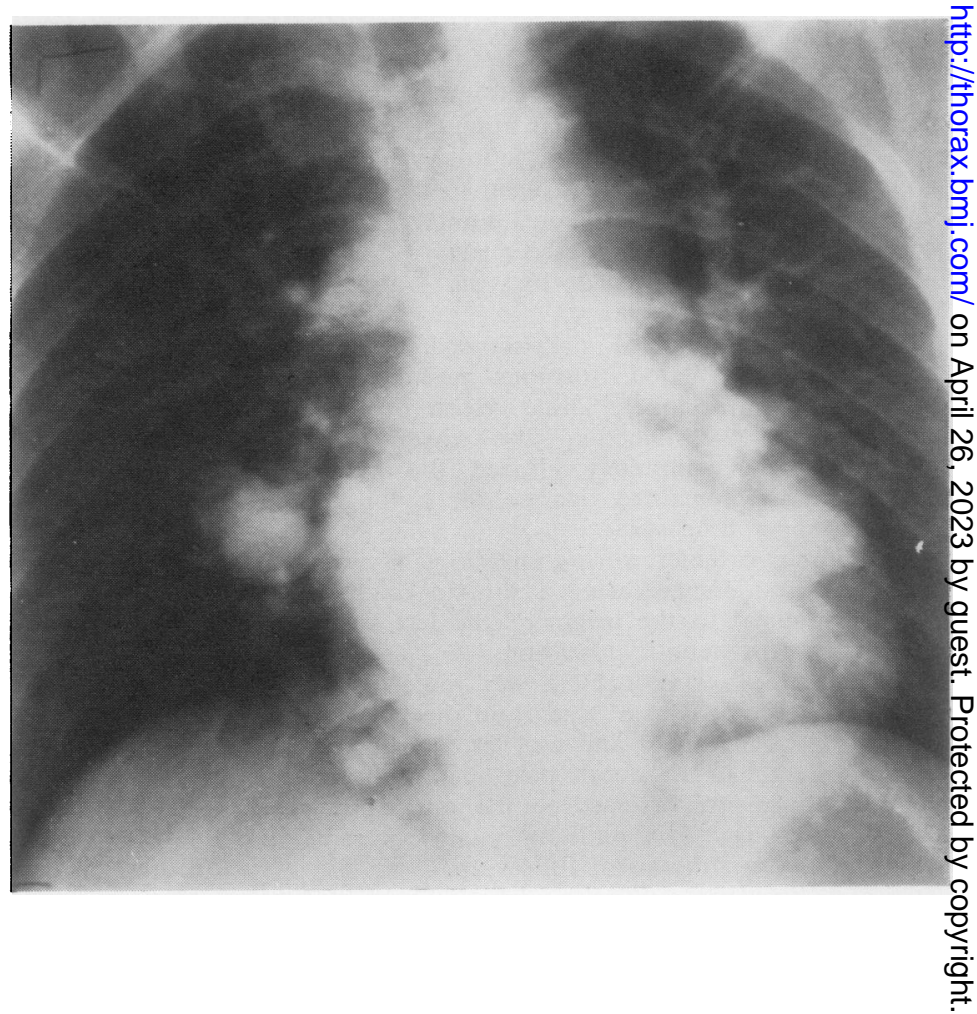




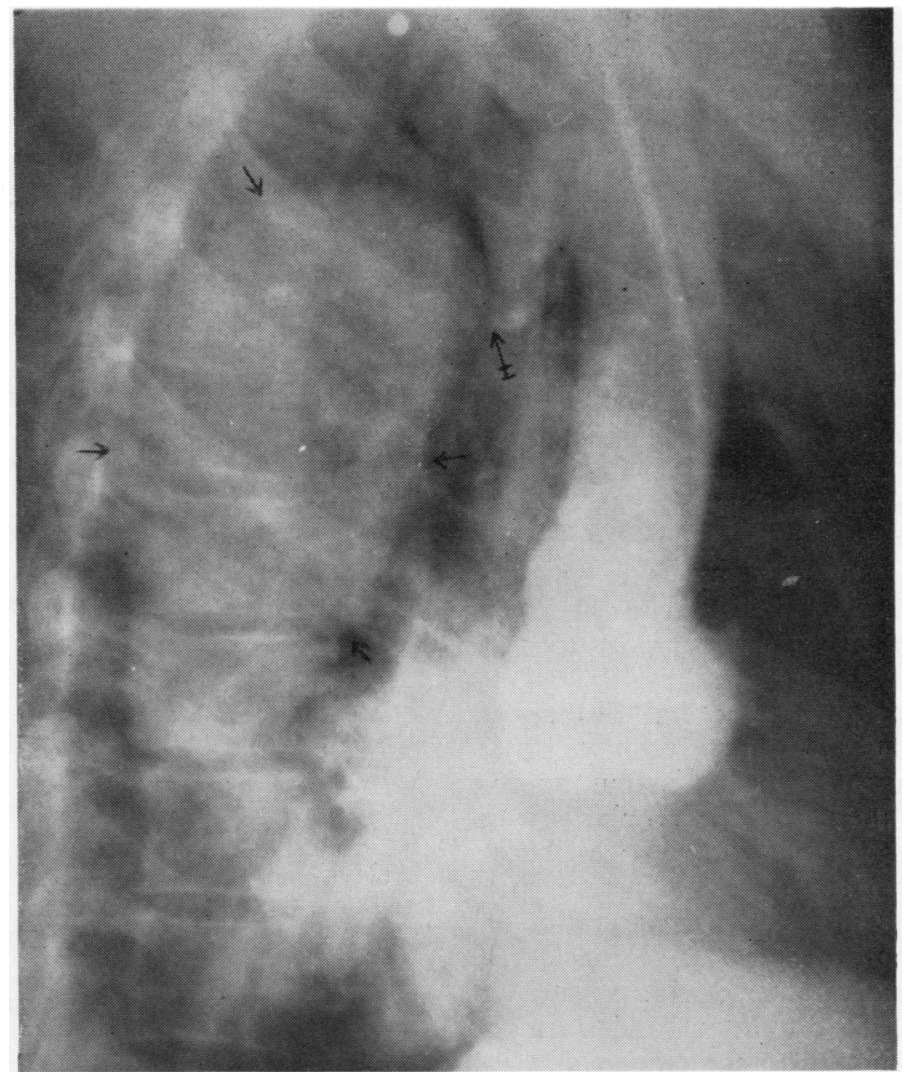

FIG. 3. Catheter aortogram. The coarcted segment and post-stenotic dilatation of the thoracic aorta are demonstrated.

1965 ; Case Records of the Massachusetts General Hospital, 1951 ; Gottesman and Weinstein, 1959 ; Hipona and Jamshidi, 1967).

In 26 the varix was single and was the only cardiovascular anomaly. In one there were multiple varices in the right lung associated with a ventricular septal defect (Vengsarkar, Kincaid, and Weidman, 1963). And in our patient there was a varix in each lower lobe and coarctation of the aorta.

In 21 patients the varix had not produced any symptoms at the time it was diagnosed.

In two it ruptured into a bronchus and in one into the pleural cavity, resulting in fatal haemorrhage (Klinck and Hunt, 1933 ; Nauwerck, 1923 ; Perret and Fortelius, 1962).

In one the varix was the suspected source of repeated brain emboli (Neiman, 1934).

One patient had his varix in the lingula and suffered from repeated pneumonias in that seg- ment, which was resected. This is the only varix treated surgically. On microscopic examination, however, the varicosity could not be incriminated as the cause of the patient's illness (Hagen and Heinz, 1960).

Another patient underwent a thoracotomy because the varix was mistaken for a tumour (Steinberg, 1967).

\section{DISCUSSION}

A pulmonary varix in most instances comes to the physician's attention as a nodular or elongated radiopacity discovered accidentally on a chest film. Often vessels are seen merging with it, thus differentiating it from solid tumours and cysts. Its vascular nature is rendered more certain by tomography and fluoroscopy. Its size would vary with the Valsalva and Muller's manœuvres. The differential diagnosis thus is narrowed down 
to a pulmonary arteriovenous fistula and varix, and this differentiation can easily be made by angiography. An arteriovenous fistula would opacify early during the arterial phase and empty quickly because of its abnormal capillary bed. On the other hand, a varix would opacify during the venous phase and lose its opacity slowly.

Pulmonary varices are regarded as congenital anomalies without any known cause. Pulmonary venous hypertension and abnormal connection of the pulmonary veins (Kozuka and Nosaki, 1968) might be contributing factors in occasional cases.

When multiple varices are present it is probably justifiable to expect other cardiovascular anomalies and to search for them.

The general tendency is to consider pulmonary varices as innocuous and to leave them without treatment; the few reported follow-ups (Hipona and Jamshidi, 1967) lend some support to this view.

But our knowledge of the natural history of varices is meagre, and in three instances fatal haemorrhage was the outcome. It is thus appropriate to follow up these patients regularly with chest films to see whether the varices show gradual alteration in size and shape before they rupture. Varices showing significant alteration in their radiographic appearance might be considered potential bleeders, and in such cases a segmental resection of the lung to prevent a fatal haemorrhage in the future should be contemplated.

\section{REFERENCES}

Bryk, D., and Levin, E. J. (1965). Pulmonary varicosity. Radiology, $85,834$.

Case Records of the Massachusetts General Hospital (1951). New $\frac{\overline{\bar{c}}}{2}$

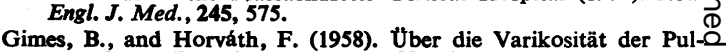
monalvene. Fortschr. Röntgenstr., 89, 545.

Gottesman, L., and Weinstein, A. (1959). Varicosities of the pul-(s) monary veins: a case report and survey of the literature. Dis.

Hagen, H., and Heinz, K. (1960). Varixknoten im Lingulaast der $\overrightarrow{-}$ Vena pulmonalis. Fortschr. Röntgenstr., 93, 151.

Hedinger, E. (1907). Demonstration eines Lungenvarix. Ver. dtsch. path. Ges., 11, 303.

Hipona, F. A., and Jamshidi, A. (1967). Observations on the natura泉 history of varicosity of pulmonary veins. Circulation, 35, 471 i

Jacchia, P. (1936). Phlebektasie im Lungenparachym. Acta radiol (Stockh.), 17, 74. Klinck, G. H., Jr., and Hunt, H. D. (1933). Pulmonary varix witho
spontaneous rupture and death. Arch. Path., 15, 227.

Kozuka, T., and Nosaki, T. (1968). A pulmonary vein anomaly음 unusual connection and tortuosity of the right lower lobe vein? Brit. J. Radiol., 41, 232.

Mouquin, M., Hébrard, H., Damasio, R., Jouvet, P., Durand, M.C and Piéquet, J. (1951). Varice du poumon diagnostiquée paé l'angiocardiographie. Bull. Soc. méd. Hôp. Paris, 67, 1091.

Nauwerck, C. (1923). Lungenvarix und Hämoptoe. Münch. med Wschr., 70, 1084.

Neiman, B. H. (1934). Varix of the pulmonary vein. Amer. J. Roent= genol., 32, 608.

Nelson, W. P., Hall, R. J., and Garcia, E. (1966). Varicosities of the pulmonary veins simulating arteriovenous fistulas. J. Amer. med. Ass., 195, 13.

Perret, L., and Fortelius, P. (1962). Ruptured aneurysm of a pule monary vein. Acta tuberc. scand., 41, 53 .

Poller, S., and Wholey, M. H. (1966). Pulmonary varix: evaluatiog by selective pulmonary angiography. Radiology, 86, 1078.

Schulze, W. (1956). Anwendung und diagnostische Bedeutung de尺 Tomographie bei Gefässanomalien und- erkrankungen in Brustraum. Förtschr. Rintgenstr., 84, 164.

Steinberg, I. (1967). Pulmonary varices mistaken for pulmonar $\vec{B}$ and hilar disease. Amer. J. Roentgenol., 101, 947.

Vengsarkar, A. S., Kincaid, O. W., and Weidman, W. H. (1963)? Selective angiography in diagnosis of varicosity of the pulmonary veins. Amer. Heart J., 66, 396. 